\title{
EVALUATION OF BIOAVAILABILITY OF RESIDUES OF PRETILACHLOR IN SOIL AND WATER UNDER PADDY CROPPING CONDITION AND THEIR INFLUENCE ON Lemna gibba
}

\author{
Rathinasamy RajaRajeswari ${ }^{1}$, Sivanandam Sathiyanarayanan ${ }^{1}$, Atmakuru Ramesh ${ }^{1}$ and Sornam \\ Ayyappan ${ }^{2}$
}

\begin{abstract}
Pretilachlor is a chloroacetanilide herbicide commonly used to control grasses, broadleaved weeds and floating aquatic species in transplanted and direct seeded rice. Herbicide residues lead to potential risk for aquatic plants and are extremely toxic to the aquatic ecosystem. Pretilachlor a chloroacetanilide herbicide, used in control of grasses, broadleaved weeds and floating aquatic species in transplanted and direct seeded rice. Herbicide residues lead to potential risk for aquatic plants and are extremely toxic to the aquatic ecosystem. The bioavailability and the toxicity of Pretilachlor residues on Lemna gibba was studied after applying the herbicide formulation at the recommended dose 1.25 g.a.i/ha under actual cropping conditions. The concentration of pretilachlor in paddy water and soil was analyzed by HPLC-UV method and its degradation products were confirmed by electrospray tandem mass spectrometry (LC-ESI -MSIMS) method. The recovery percentage at the limit of quantification (LOQ) 0.03 ppm was 92-102\%. Residues in water dissipated rapidly with DT50 value 1.6 days and went to below detectable level by 15thday. The percentage inhibition of yield based on frond numbers was $97 \%$ at this time point, indicating toxicity index $(\mathrm{TI})>1.0$ to Lemna gibba. The observation recorded on $90^{\text {th }}$ day showed no sign of inhibition of yield of Lemna gibba.
\end{abstract}

Key words: Cropping, Dissipation, LC-ESI -MS/MS, Lemna gibba inhibition, Pretilachlor, Toxicity index value.

\section{INTRODUCTION}

Pretilachlor is a chloroacetanilide herbicide used in control of grasses, broadleaved weeds and floating aquatic species in transplanted and direct seeded rice (Oryza sativaL). The finding is consistent with the observed effect of fenclorim on pretilachlor persistence and detoxification in the rice shoots (Scarponi et al., 2003). Pretilachlor is a relatively non persistent herbicide with $50 \%$ degradation time values of 3.5 and 7 to 10 days in paddy water and sediment, respectively (Fajardoet al., 2000). The environmental fate of pretilachlor and esprocarb studied in soil with or without spherosomes indicates influence of the factors such as microorganisms, soil constituents and physico-chemical properties (Adachi et al., 2007). The herbicide mobility and fate in soil are influenced by sorption and degradation processes apart from physical and chemical properties of the pesticide, organic-carbon and mineral-surface sorption coefficients and aqueous solubility (Savoca, 2000). Pretilachlor was disappeared from water by adsorption to

${ }_{1}$ International Institute of Bio-technology and Toxicology (IIBAT), Department of Analytical Chemistry, raamesh_a@yahoo.co.in 
soil and rapidly degraded under practical conditions, under laboratory condition the half life was $~ 30$ days due to strong soil adsorption. The major breakdown pathway for chloroacetanilide pesticides in soil is due to presence of aerobic and anaerobic microorganisms. These herbicides were transformed by soil microorganisms and primarily degraded into two derivative products as ethane sulfonic acid (ESA) and oxanilic acid (OA) has been suggested to occur as a result of displacement of chlorine atom of the parent compound by glutathione, followed by formation of ESA and OA degradates by different enzymatic pathways (Barbash et al., 1999). The pretilachlor has higher adsorption on the sediment suggest that pretilachlor disappearance from the water was mainly the result of degradation during the period of 18 to 27 days after pesticide application under field conditions (Vidotto et al., 2004). PDPF-1 (pesticide concentrations in paddy water) model prediction of pretilachlor was evaluated $3.0 \mathrm{~cm}$ and $1.0 \mathrm{~cm}$ per distance of continuous overflow drainage practices may potentially lose $74 \%$ and $63 \%$ of applied herbicide to the surface water and ground water due to field drainage and percolation rates resulting from different management practices (Hirozumi and Kazuhira, 2000). Investigations on the degradation process in waste water by electrocatalysis oxidation process of pretilachlor also showed the presence of intermediates/primary degradation products. The above investigation of the degradation pathways contained hydroxylation, oxidation, dechlorination, $\mathrm{C}-\mathrm{O}$ bond and $\mathrm{C}-\mathrm{N}$ bond cleavage, resulting the formation of nine main intermediates were confirmed by GC-MS (Wei et al., 2011). Recent investigations on pretilachlor are mainly concentrated on the fate of pretilachlor after contact with the environment (Posecion et al., 2006; Tsuda et al., 2009 and Inderjit 2010). Paddy herbicides are of high-risk concern for aquatic plants, because they easily flow out from paddy fields into rivers, with toxic effects (Nagai et al., 2011). The presence of herbicide residues in surface water, soil leads to potential risk for aquatic plants. The residues of chloroacetanilide herbicides are extremely toxic to the aquatic organism caused the long-term adverse effects to the aquatic environment. Among the rice pesticides, pretilachlor is one of the most applied in the flooded rice fields to control weeds through inhibition of photosynthesis (Mitsou et al., 2005).

The objective of the study was to investigate the dissipation of pretilachlor in water and soil under actual cropping condition and simultaneously evaluating the Percentage of Inhibition on Yield and toxicity index value of Lemna gibba till harvesting.

\section{MATERIALS AND METHODS}

Commercially available pretilachlor 50\% EC (Emulsifiable concentrate) formulation and certified analytical reference standard of Pretilachlor of purity $98.3 \%$ supplied by Riedel-de-haen, Sigma Aldrich Laboratory Chemicals GmbH -D-30296 was used in this study. Hexane, Acetone, aluminium oxide and diethyl ether were purchased from Sigma Aldrich Chemicals with AR grade. Lemna gibba culture is obtained from Germany and maintained in IIBAT (International Institute of Biotechnology and Toxicology, India). 


\section{EXPERIMENTAL DETAILS}

ADT-43 variety of paddy rice seed was used in this study. Plot size of $10 \mathrm{sq} . \mathrm{m}$. was located in Agricultural Farm, IIBAT, padappai. The age of the crop at the time of spray (Recommended dose at $1.25 \mathrm{~kg} \mathrm{a.i} / \mathrm{ha}$ ) was 10days after transplanting paddy. Lemna gibba was exposed separately to the paddy water at different occasions (both treatment and control) with known number of Lemna fronds to calculate the percentage of inhibition of yield till harvesting. The soil and water samples were collected for residue analysis with occasion of $0,5,10,15,30,50,70$ and 90 days. The same above occasions were used for Lemna toxicity evaluation in paddy water to calculate the percentage inhibition of yield based on frond.

\section{HPLC-UV Conditions}

The concentration of pretilachlor in paddy water and soil was analyzed by HPLC

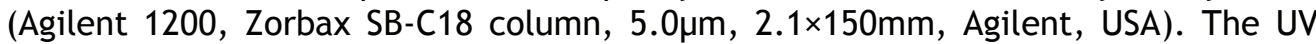
detected wavelength was set as $210 \mathrm{~nm}$, Acetonitrile/Water $(90 / 10$, v/v) with $1 \mathrm{~mL}$ min-1 was used as flow phase, and amount of sample injection was $20 \mu \mathrm{L}$. High Capacity Ion Trap (HCT plus) LC-MS/MS system supplied by Bruker Daltonik, GmbH, Germany, Agilent 1200 HPLC system with gradient elution of $0.5 \mathrm{ml}$ per minute having $0.1 \%$ formic acid in acetonitrile as mobile phase A, $0.1 \%$ formic acid in Milli$\mathrm{Q}$ water as mobile phase B were used to separate the intermediates/primary degradates and pretilachlor. Drying gas nitrogen was generated using the Nitrox UHPLCMS nitrogen generator at a flow rate of $7.0 \mathrm{lit} / \mathrm{min}$. The nebulizer gas was set at 40 psi and dry temperature $340^{\circ} \mathrm{C}$.

\section{Extraction Procedure (water and soil)}

A $20 \mathrm{ml}$ aliquot of water from the paddy field was collected and filtered using Whattman 41 filter paper. Samples were analyzed by HPLC and LC-MS/MS-ESI under the conditions described above by direct injections for both parent and primary degrades.

Weighed $50 \mathrm{~g}$ of homogenized soil sample into a $500 \mathrm{ml}$ Erlenmeyer flask and extracted pretilachlor residues twice with $100 \mathrm{ml}$ of methanol using an end-overend mechanical shaker, filtered the extract and concentrated to $20 \mathrm{ml}$ using a rotary-vacuum evaporator. Transferred the concentrated extract to $500 \mathrm{ml}$ separatory funnel and added $75 \mathrm{ml}$ of $5 \% \mathrm{NaCl}$ solution and extracted the aqueous solution twice with $100 \mathrm{ml}$ of $\mathrm{n}$-hexane by vigorously shaking the separatory funnel for 2 minutes. The $n$-hexane phases are collected after filtering through a plug of cotton and evaporated to dryness using a rotary vacuum evaporator at $40^{\circ} \mathrm{C}$. A chromatographic column of 1 meter length was filled with alumina basic grade $v$, using $n$-hexane, drained the solvent and transferred the residues to the column using hexane. The column was rinsed with $100 \mathrm{ml}$ of $\mathrm{n}$-hexane and discarded the eluate. The residues were eluted using $100 \mathrm{ml}$ of $\mathrm{n}$-hexane + ethyl ether $(2: 1)$ mixture and collected the eluate. The collected eluate was concentrated to near dryness under vacuum at $40^{\circ} \mathrm{C}$, the residues were reconstituted using residue grade 
acetonitrile for HPLC analysis of active and LC-MS/MS-ESI analysis for metabolite determination.

\section{Evaluation of Percentage of Inhibition on Yield of Lemna gibba}

Plants of the Lemna gibba were allowed to grow as monocultures in recommended test dosage (1.25 kg a.i./ha) over a period of seven days intervals till harvesting. The substance-related effect on vegetative growth over this period was evaluated based on assessments of frond number. To quantify substance-related effects, growth in the test solutions is compared with controls and the concentration bringing about a specified percentage inhibition of yield based on frond numbers. The percent inhibition of the yield $\left(\% \mathrm{I}_{\mathrm{y}}\right)$ at the test concentration (recommended dose of pretilachlor-1.25 kg a.i. / ha) was calculated using the following equations,

$$
\% I_{y}=\left(Y_{c}-Y_{t}\right) \times 100 / Y_{c}
$$

where, $\% \mathrm{I}_{\mathrm{y}}$ is the percent inhibition of yield based on frond numbers, $Y_{C}$ is the mean value for yield in the control and $Y_{t}$ is the mean value for yield in the treatment group. The doubling time of frond number in the control is 2.33 days which is less than 2.5 days (60 hours) and the $\mathrm{pH}$ of the control field is 8.66 which are recorded in the limit of 1.5 units during the test. Based on the above results, the present test is validated.

\section{Evaluation of Toxicity Index}

Acute toxicity data of chloroacetamide herbicides are primarily collected from the EPA's ECOTOX DATABASE (U.S. EPA, 2001) and other sources were also used (Helfrich et.al 1996; Fairchild et al., 1997; Fairchild et al., 1998; Okamoto et al., 1998 and Sparling et al., 2000). Published EC $_{50}$ values for aquatic plant duckweed were used as toxicity metrics in this study.

Toxicity index $(\mathrm{TI})$ value $=$ Concentration of pretilachlor $/ \mathrm{EC}_{50}$ value of pretilachlor

$\mathrm{TI}$ values $>1.0$ indicates probable toxicity pesticides, $\mathrm{TI}$ values $>0.5$ indicates potential toxicity and TI values $>0.1$ indicates limited toxicity to aquatic plants.

\section{RESULTS AND DISCUSSIONS}

\section{METHOD VALIDATION}

The specificity for Pretilachlor was determined by Injecting the control samples, mobile phase, Milli-Q water and acetonitrile. The method was found to be linear with a correlation coefficient of 1.000 when tested in the concentrations of linearity solutions $10.0,5.0,2.0,1.0,0.5,0.1$ and $0.01 \mathrm{ppm}$ were prepared by serial dilution method using mobile phase and injected in HPLC-UV. The limit of detection was determined as $0.01 \mathrm{ppm}$ based signal to noise ratio 3:1. The recovery study was done in Milli-Q water by fortifying the concentration of LOQ and $5 \times$ LOQ. 
Six replicate determinations were made at each concentration level for repeatability analysis. The method had an acceptable recovery $92-102 \%$ in Clay soil and water. The limit of quantification (LOQ) was established as $0.03 \mathrm{ppm}$. The related standard deviation (RSD) \% for each concentration studied was calculated using 'Horwitz equation'.

RSD\% $<2^{(1-0.5 \log C)} \times 0.67$ (C - concentration of the pretilachlor expressed in percentage)

\section{PERSISTENCE IN SOIL AND WATER}

The residues in soil samples collected on different occasions and half life of Pretilachlor calculated from the dissipation data at recommended dosages in clay soil under cropping condition. Analysis of soil samples showed the presence of pretilachlor residues upto 50 days under cropping condition, the analysis of $70^{\text {th }}$ day samples showed the residues below detectable level. The half-life of pretilachlor in soil under flooded field condition was 30.13 days. The dissipation of pretilachlor in water under field condition was calculated and the residue found below detectable level on $15^{\text {th }}$ day residues. The half-life of pretilachlor in water under flooded field condition was 2.0 days.

\section{BIO-ANALYSIS}

Pre-culture of Lemna gibba was performed eight days after initiation of the study. The inoculated flasks were kept in the growth cabinet and maintained with continuous illumination of 6738 - 6935 lux light intensity at 23.5 to $24.8^{\circ} \mathrm{C}$ for eight days. After transplanting paddy crop, acclimatization of Lemna gibba was done for 10 days, the test solution was sprayed in the field after the acclimatization period and the $\mathrm{pH}$ was recorded as 7.24. After measurement of $\mathrm{pH}$, the control and treated field were inoculated with equal numbers of Lemna gibba plants (10 fronds) from 8 day old test culture under aseptic conditions. During the laboratory experimental period, the temperature in the test medium was $23.3-24.3^{\circ} \mathrm{C}$ and the light intensity was recorded with the range of 6757 to 6875 lux under direct sunlight. The number of fronds and their appearance were recorded on day 7 . At the tested concentration (recommended dose) on day 7, some morphological changes such as shorter roots, slightly concaved fronds (Gibbosity), chlorosis, smaller fronds and necrosis were observed. The results of percentage inhibition of yield based on frond numbers of Lemna gibba was calculated during the period on different occasions of paddy field. TI value is greater than 1.0 till on $15^{\text {th }}$ day, it indicates that the concentration of pretilachlor in paddy water was highly toxic to Lemna gibba and the higher values of percentage inhibition of yield.

\section{Interaction of dissipation data and toxicity evaluation of Lemna gibba}

The summary of both dissipation data of pretilachlor and percentage inhibition of yield of Lemna gibba in paddy field at different days were presented in Table 1. 
Table 1. Data of Pretilachlor and \% inhibition of growth rate and yield of Lemna gibba in paddy field

\begin{tabular}{lllllllll}
\hline Occasions (days) & 0 & 5 & 10 & 15 & 30 & 50 & 70 & DT50 \\
conc (ppm) in soil & 0.652 & 0.641 & 0.630 & 0.618 & 0.412 & 0.210 & BDL & 30.13 \\
conc (ppm) in water & 0.685 & 0.253 & 0.021 & BDL & - & - & - & 2.0 \\
Occasions (days) & 0 & 5 & 10 & 15 & 30 & 50 & 70 & 90 \\
ly\% & 100 & 100 & 100 & 97 & 80 & 30 & 7 & 0 \\
\hline
\end{tabular}

Note: BDL - Below Detectable Limit, ppm - parts per million

The $100 \%$ inhibition of yield was observed at $0.685 \mathrm{ppm}$ concentration in paddy water initially. After the residues of pretilachlor get dissipated to below detectable level on $15^{\text {th }}$ day in water and at this occasion the growth inhibition of yield was $97 \%$ respectively. This is due to the toxicity effect of pretilachlor $(\mathrm{TI}>1.0)$ and also the degradates were present in the paddy water. The degradates are more persistent than the parent compound, found in higher concentrations and more frequently on surface and ground water than pretilachlor (Rivard, 2003).

\section{CONFORMATION OF RESIDUES AND ITS DEGRADATES}

The degradation pathway of pretilachlor in water and soil was presented in Figure 1. The presence of residues and its degradates were confirmed by analyzing the extracts of water and soil samples using LC-MS/MS-ESI. The herbicide, Pretilachlor got eluted at 13 minutes and showed a molecular ion peak at $\mathrm{m} / \mathrm{z} 312$, the fragment ions were appeared at 252 and 176, confirms the residues of pretilachlor in samples and the details are presented in Table 2. The representative LC-ESIMS/MS spectra of pretilachlor and its breakdown products were presented in Figure 2 respectively.

Table 2. LC-ESI-MS/MS fragmentation ions of pretilachlor and its breakdown products

\begin{tabular}{|c|c|c|c|}
\hline Compound name & Molecular mass & Molecular ion & Fragment ions \\
\hline Pretilachlor & 311 & 312 & 252,176 \\
\hline 2-acetyl-6-ethyl-N-(propyloxyethyl)acetanilide & 293 & 294 & 234,176 \\
\hline Metabolite - Hydroxylalachlor & 327 & 328 & 268,252 \\
\hline $\begin{array}{l}\text { Metabolite-2-chloro-1-(9-ethyl-3-hydroxy-2,3,4,5- } \\
\text { tetrahydro-1H-1-benzazepin-1-yl)ethanone }\end{array}$ & 267 & 268 & 220,137 \\
\hline 2,6-diethyl-N-(propyloxyethyl)aniline & 235 & 236 & $176,148,120$ \\
\hline 2,6-diethyl-N-(propyloxyethyl)acetanilide & 277 & 278 & 218,176 \\
\hline
\end{tabular}




\section{CONCLUSIONS}

Three conclusions can be drawn from the above results of this investigation. First, there is a huge difference in dissipation of pretilachlor in soil and water under actual cropping conditions and the $\mathrm{DT}_{50}$ values are 30.13 and 2.0 respectively. The values indicated that pretilachlor disappeared rapidly in water due to strong soil adsorption. Second, Pretilachlor residue get dissipated to below detectable level on $15^{\text {th }}$ day in water and at this occasion the growth inhibition was $97 \%$ due to the presence of the primary degradation products of pretilachlor in paddy water. Finally, the toxicity index $(\mathrm{TI})$ value on $15^{\text {th }}$ day sample $(>1.0)$ indicated that highly toxicity to Lemna gibba. The above conclusions were identified that the importance of quantifying both parent compounds and degradates to fully understand the environmental fate and transport of herbicides in the hydrologic system using Lemna as biological marker.

\section{ACKNOWLEDGEMENT}

The authors are grateful to Dr. P. Balakrishamurthy, Director of IIBAT and Management for providing necessary facility to conduct the research work.

\section{REFERENCE}

Adachi, A., Komura, T., Andoh, A.and Okano,T., 2007. Effect of Spherosomes on Degradation of Pretilachlor and Esprocarb in Soil. Journal of Health Science, 53(5): 600-603.

Barbash, J.E., Thelin, G.P., Kolpin D.W. and Gilliom, R., 1999. Distribution of major herbicides in ground water of the United States. U.S. Geological Survey, WaterResources Investigations, Saramento, CA, Report 98-4245.

Fajardo, F.F., Takagi,K., Ishizaka, M. and Usui, K., 2000. Pattern and rate of dissipation of pretilachlor and mefenacet in plow layer and paddy water under lowland field conditions: a three-year study. Journal of Pesticide Science, 25:94-100.

Fairchild, J.F., Ruessler, D.S., Haverland P.S. and Carlson, A.R., 1997. Comparative sensitivity of Selenastrum capricornutum and Lemna minor to sixteen herbicides. Archives of Environmental Contamination and Toxicology, 32:353-357.

Fairchild, J.F., Ruessler, D.S. and Carlson, A.R., 1998. Comparative sensitivity of five species of macrophytes and six species of algae to atrazine, metribuzin, alachlor, and metolachlor. Environmental Toxicology and Chemistry,17(9):1839-1834.

Helfrich, A., 2009. Pesticides and aquatic animals: a guide to reducing impacts on aquatic systems. Virginia Cooperative Extension Publication, 420-013.

Hirozumi, W. and Kazuhiro, T., 2000. Prediction of pretilachlor concentrations in paddy water and paddy surface soil by PCPF-1 model and the model application for controlling pesticide losses from paddy fields. Transactions of the Japanese Society of Irrigation, Drainage and Reclamation Engineering, 209:641-648.

Inderjit, S.K., 2010. Effect of herbicides with different modes of action on physiological and cellular traits of Anabaena fertilissima. Paddy Water Environment, 8:277-282.

Iwafune, T., Inao, K., Horio, T., Iwasaki, N., Yokoyama, A. and Nagai, T., 2010. Behavior of paddy pesticides and major metabolites in the Sakura River, Ibaraki, Japan. Journal of Pesticide Science, 35(2):114-123. 
Mitsou, K., Koulianou, A., Lambropoulou, D., Pappas, P., Albanis, T. and Lekka, M., 2005. Growth rate effects, responses of antioxidant enzymes and metabolic fate of the herbicide Propanil in the aquatic plant Lemna gibba. Chemosphere, 2:275-284.

Nagai, T., Ishihara, S., Yokoyama, A. and Iwafune, T., 2011. Effects of four rice paddy herbicides on algal cell viability and the relationship with population recovery. Environmental Toxicology and Chemistry / SETAC, 30(8):1898-905.

Okamoto, Y., Richard, L., Fisher, L., Kevin, L., Armbrust, L. and John Peter, C., 1998. Surface water monitoring survey for bensulfuron methyl applied in paddy fields. Journal of Pesticide Science,23(3):235-240.

Posecion, N., Ostrea, E., Bielawski, D., Corrion, M., Seagraves, J. and Jin,Y., 2006. Detection of exposure to environmental pesticides during pregnancy by the analysis of maternal hair using GC-MS. Chromatographia 64:681-687.

Rivard, L., 2003. Environmental Fate of Metolachlor. Environmental Monitoring Branch, Department of Pesticide Regulation, 1001 I Street, Sacramento, CA 95812.

Sparling,D.W., Linder, G., Bishop, C.A. and Krest, S., 2000. Ecotoxicology of organic contaminants to amphibians. In: Ecotoxicology of Amphibians and Reptiles. CRC Press. pp. 261-288.

Savoca,M.E., 2000. Effects of land use and hydrogeology on the water quality of alluvial aquifers in Eastern lowa and Southern Minnesota, 1997. U.S. Geological Survey, WaterResources Investigations Report, pp. 99-4246.

Scarponi, L., Del Buonoa, D., and Vischettib, C., 2003. Persistence and detoxification of Pretilachlor and Fenclorim in rice (Oryza sativa). Agronomie, 23 (2):147-151.

Tsuda, T., Nakamura, T., Inoue, A. and Tanaka,K.,2009. Pesticides in water, fish and shellfish from littoral area of lake Biwa. Bulletin of Environmental Contamination and Toxicology, 82:716-721.

U.S. EPA, 2001. U.S. Environmental Protection Agency ECOTOX database. Accessed 3/2001 at http://www.epa.gov/ecotox/

Vidotto, F., Ferrero, A., Bertoia, O., Gennari, M. and Cignetti, A., 2004. Dissipation of pretilachlor in paddy surface water and sediment. Agronomie, 24:473-479.

Wei, J., Feng, Y., Sun, X., Liu, J. and Zhu, L., 2011. Effectiveness and pathways ofelectrochemical degradation of pretilachlor herbicides. Journal of Hazardous Materials, 189: 84-91. 


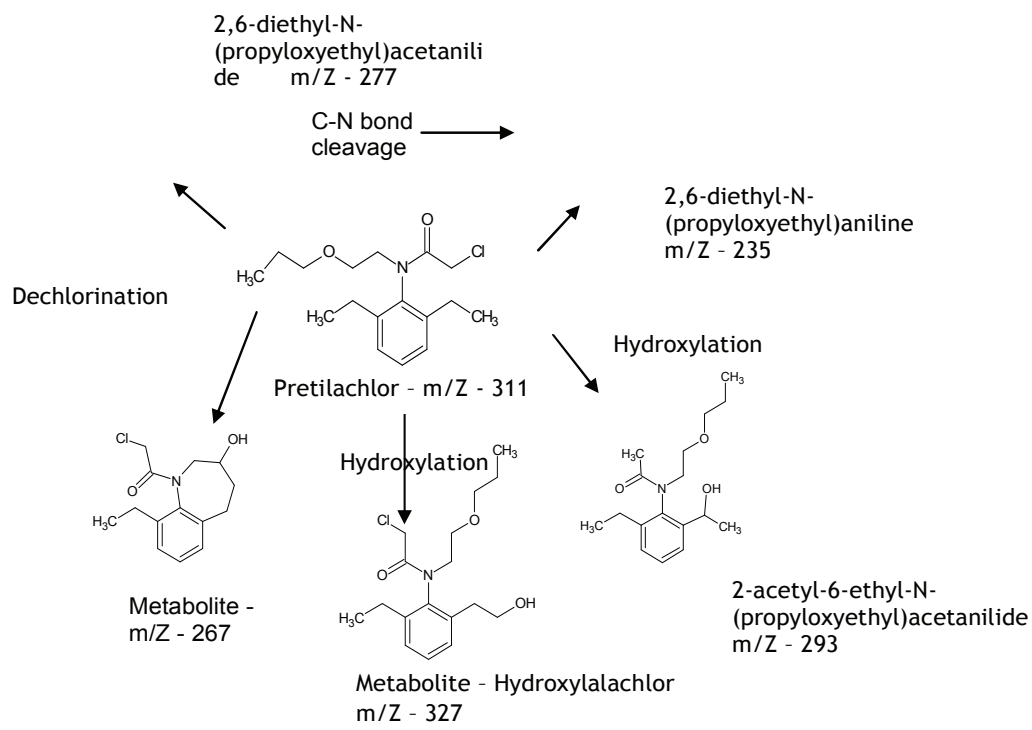

Figure 1. Degradation pathway of Pretilachlor
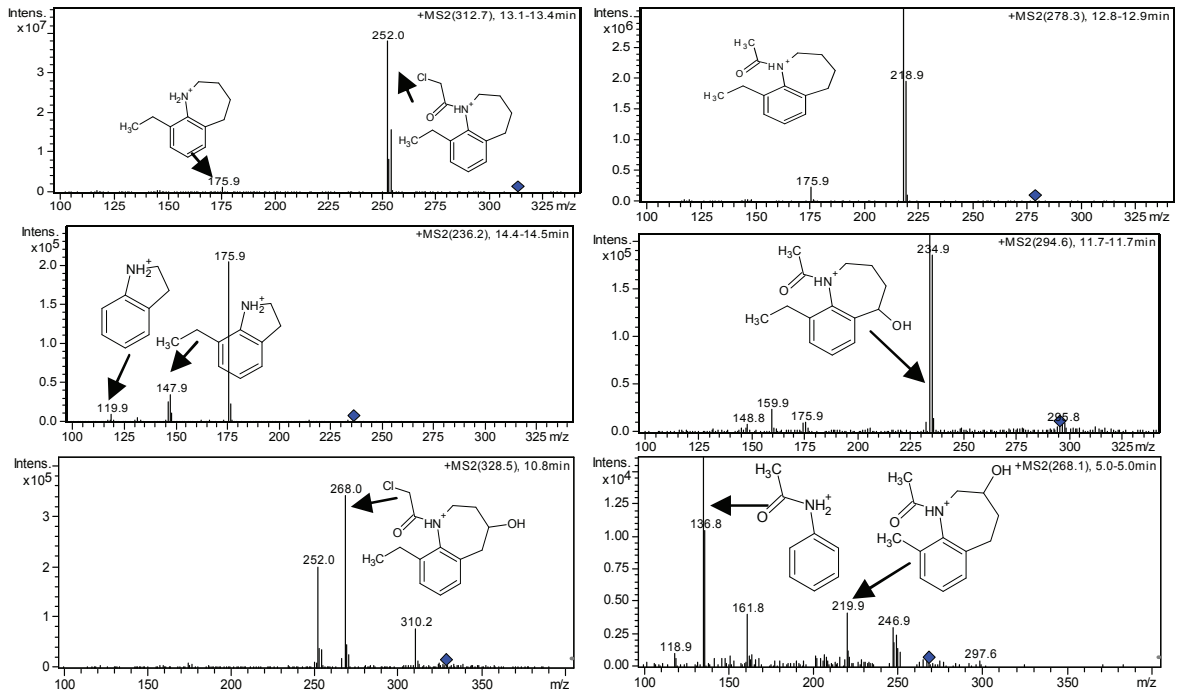

Figure 2. LC-ESI-MS/MS Spectra of pretilachlor and its breakdown products in soil and water. 